Sakurai, Y., Shimauchi, S., Shimmi, Y., Amaki, Y., Hanada, S., \& Elliot, D.

(Accepted). Competing meanings of international experiences for early-career

researchers: A collaborative autoethnographic approach. Higher Education Research and Development. (preprint doi: https://doi.org/10.35542/osf.io/a6xug)

\title{
Competing Meanings of International Experiences for Early-Career Researchers: A Collaborative Autoethnographic Approach
}

Yusuke Sakurai ${ }^{\text {a*, Sae Shimauchi }}{ }^{\mathrm{b}}$, Yukiko Shimmi ${ }^{\mathrm{c}}$, Yuki Amaki ${ }^{\mathrm{d}}$, Shingo

Hanada $^{\mathrm{e}}$ and Dely Lazarte Elliot ${ }^{\mathrm{f}}$

${ }^{a}$ Ochanomizu University, Japan; ${ }^{b}$ Tokyo Metropolitan University, Japan; ${ }^{c}$ Tohoku

University, Japan; ${ }^{d}$ Taisho University, Japan; ${ }^{e}$ Toyo University, Japan; ${ }^{f}$ University of

Glasgow, UK

${ }^{a}$ sakurai.yusuke@ocha.ac.jp, https://orcid.org/0000-0003-1150-3132

${ }^{b}$ https://orcid.org/0000-0002-0409-2526

${ }^{c}$ https://orcid.org/0000-0003-2082-0578

${ }^{d}$ https://orcid.org/0000-0002-6794-8870

${ }^{e}$ https://orcid.org/0000-0002-2857-1353

${ }^{f}$ https://orcid.org/0000-0003-0711-5719 


\title{
Competing Meanings of International Experiences for Early-Career
} Researchers: A Collaborative Autoethnographic Approach

\author{
Although there is a pressing demand for international experience for early career \\ researchers (ECRs), the meaning of this experiences arising from their day-to-day \\ work responsibilities is still unclear. Accordingly, using our emic reflections for \\ this autoethnographic study, we-five Japanese ECRs with years of international \\ experiences - collaboratively explored how we made sense of our international \\ experiences, that is, our distinct capital attained from international study and \\ research experiences. We used Identity Trajectory as a conceptual tool to widely \\ capture ECRs' key experiences and sense-making. Our reflective conversations \\ resulted in five major themes: (1) global personal network, (2) communicative \\ competence, (3) scholarly community culture, (4) scholarly ambition and (5) \\ pedagogical application. We consistently valued our attained capital, but \\ simultaneously recognised dilemmas while engaging in our work. Lack of \\ institutional support was critical, preventing us from using our international \\ experiential capital and further developing as internationally active researchers. \\ This study offers insights for those who may consider an academic career in \\ Japan after returning from international sojourns and for policymakers promoting \\ the internationalisation of Japanese higher education. Studies such as this one \\ also contribute to the exploration of the value of international experiences for \\ researchers in different contexts.
}

Keywords: international experience, early career researchers, autoethnography, Japan 


\section{Introduction}

A rapidly changing society demands diverse and dynamic university communities (Horta \& Yudkevich, 2016). In response, the number of researchers who have studied overseas or had overseas academic experience has been increasing (e.g., Jonkers \& Tijssen, 2008). In Japan, the number of local researchers with overseas degrees has increased 3\% annually over the past five years at major universities (Japan Society for the Promotion of Science, 2020). The rationale of mobility has more often been discussed for economic, institutional or national benefits than for individual researchers who travel (Melin, 2005). Thus, little is known about how individual researchers make sense of the value of their international academic experience (e.g., Israel et al., 2019; Wang, 2020). We therefore employed an in-depth autoethnographic approach to unpack five Japanese early career researchers' nuanced sense-making of international experiences in the field of education. According to the broad literature, transition to new academic roles for early career researchers (ECRs) is at times likened to a bumpy road (McAlpine \& Amundsen, 2017). Despite returning to their home country, they may face challenges in fitting in to their new workplaces (e.g., Melin, 2005).

\section{ECRs Making Sense of their Experiences: Past, Present and Future}

Researchers make day-to-day decisions based on their understanding of their past, their immediate work experiences and their vision for the future (e.g., McAlpine \& Amundsen, 2017). Newly-hired researchers understand unfamiliar institutional practices by drawing on what they previously experienced (McAlpine \& Amundsen, 2011). The notion of "identity-trajectory" (McAlpine \& Amundsen, 2017) offers a theoretical lens

through which to investigate ECRs' experiences and context-dependent ongoing sense- 
making of their work. The notion conceptualises ECRs' being, becoming and performing as academics by identifying their activities as situated in their work and personal settings. McAlpine and Amundsen (2017) presented three key strands in understanding ECRs' experience: intellectual, networking and institutional. The intellectual strand includes one's scholarly activities and contribution through publication, presentations and education. Examples include the demanding but rewarding publication processes, inspiring conversations via publications and in conferences, practical application of research findings, and advising students (McAlpine \& Amundsen, 2017; Turner \& McAlpine, 2011). The networking strand represents one's interpersonal relationships and sense of membership in local, national and international communities. It also includes both formal and informal opportunities (McAlpine \& Amundsen, 2017). ECRs make use of and contribute to the network where they obtain emotional and professional support (Elliot et al., 2020). ECRs' knowledge of intertextual "networks" in the broad literature is also key for their expertise (McAlpine \& Amundsen, 2017). The institutional strand refers to resources and responsibilities in one's workplace or external affiliations. Research facilities, training, job (in)security, managerial support and responsibilities may influence ECRs' work, development and sense of belonging (McAlpine \& Amundsen, 2017). The three strands are interrelated and not necessarily mutually exclusive. The framework helps ECRs understand their responsibilities and further envision their future selves in academia (McAlpine \& Amundsen, 2011). 


\section{ECRs' International Experience as Capital}

Mobility experiences can be conceptualised as capital. Capital refers to one's accumulated experience, achievements and acquired qualities that would catalyse as resources and generate further benefits or drawbacks (Bourdieu, 1986; Portes, 1998). To Bourdieu (1986), capital is threefold: economic, cultural and social. Economic capital refers to financial and property resources which are immediately convertible into money. Social capital is one's relationships with groups and individuals in particular societies. Cultural capital is an amalgam of both symbolic and tangible materials, knowledge, skills, behaviours and credentials which one attains in a particular society. In our analysis, two types of capital — social and cultural — are particularly relevant, although one can indirectly attain economic capital, such as wages and research grants, via a position where particular forms of social and cultural capital are valued.

International experiences often convey cultural and social capital, such as one's language competence, personal growth, intercultural sensitivity, employability, local knowledge and interpersonal network (e.g., Crossman \& Clarke, 2010; Elliot et al., 2020; Hanada, 2019; Ota \& Shimmi, 2019). Researchers in particular equip themselves with functional academic communication skills (Li et al., 2018), scholarly ambitions (Li et al., 2018; Zweig et al., 2004), research techniques (Jonkers \& Tijssen, 2008; Melin \& Janson, 2006; Zweig et al., 2004) and ability to participate in international activities (Horta \& Yonezawa, 2013; Jonkers \& Tijssen, 2008). The value of capital is context dependent (Bourdieu, 1986; Israel et al., 2019). Hence, returnee academics may or may not find their cultural and social capital valuable at their new workplaces. The conceptual tool—identity-trajectory—complements a theoretical understanding of returnees' context-dependent sense-making of their international experiences. 
Returnee ECRs' cultural capital such as novel knowledge and techniques can contribute to the intellectual activities of local communities (Choi \& Lu, 2013; Li et al., 2018; Zweig et al., 2004). They may promote the global competitiveness of local scholarly communities (Melin \& Janson, 2006; Xu, 2009). However, returning researchers may find the transborder transition stressful, as even conditions at home may be unfamiliar after living abroad (Ai \& Wang, 2017). Their intellectual assets may not always be positively evaluated locally (Ai \& Wang, 2017; Melin, 2005; Yi, 2011). They may be disappointed that their workplace is secluded from international dialogues where their social capital is useful (Xu, 2009). Furthermore, returnees may feel perplexed by locally-educated academics' expectation to contribute more locally than internationally (Ai \& Wang, 2017). In addition, researchers who have spent years abroad may also display a lack of knowledge about grant writing in their new contexts. This ignorance imposes new challenges, especially in terms of continuing their intellectual activities (McAlpine \& Amundsen, 2011). Accordingly, returnees may find themselves caught between local and international intellectual communities (Ai, 2019) or lose their will to further their transborder expertise (Xu, 2009).

In addition to research work, returnee ECRs may be a new intellectual asset to their universities by using their cultural capital, including novel knowledge and pedagogical approaches, in their teaching (Choi \& Lu, 2013; Li et al., 2018; Zweig et al., 2004). However, some mobile ECRs have trouble performing their teaching responsibility effectively due to their unfamiliarity with local norms (Robles \& Franzoni, 2015). Returnees may also face confusion from students who have different instructional expectations (Ai \& Wang, 2017). 
Sound institutional conditions are also key for ECRs' expertise development. Sufficient funding, life-long learning opportunities and management assistance are necessary resources for productivity in pioneering research (Darmoe, 2017). However, local bureaucracy and administrative formalities prevent them from working efficiently (Wang, 2020) and presenting quality research globally (Xu, 2009). Inappropriate research assessment strategies also disappoint returnees (Ai, 2019). Moreover, ECRs, especially those crossing borders, are often situated at peripheral positions in institutions without sufficient access to support systems (Brotherhood et al., 2019; Takagi, 2018). For example, it may take a while for these researchers to establish an efficient work environment at a new institution (Jonkers \& Tijssen, 2008; Li et al., 2018; Melin, 2005).

Even when most colleagues are fellow countrypersons, returnees may feel isolated due to the different forms of cultural and social capital they have acquired (e.g., Ai, 2019). For example, a Chinese returnee sensed a disparity between their own and their colleagues' work expectations. Soliciting explicit clarifications about unwritten rules, however, may generate unwanted friction (McAlpine \& Amundsen, 2011). Further, returnees often felt disappointed about local colleagues' greater emphasis on institutional consensus than on innovative activities (Ai \& Wang, 2017). Others acknowledged the lack of critical but supportive conversation in Chinese academia, which impeded the development of a healthy intellectual climate (Yi, 2011). Poor workplace integrity and bureaucratic management result in cynicism and disappointment (Yi, 2011). Accordingly, although many returnees are active both domestically and internationally (Ai, 2019; Li et al., 2018; Wang, 2020), some may feel little sense of belonging in their local communities (Yi, 2011). 
Networking supports ECRs' advancement and visibility in institutions and scholarly communities. It also encourages their emotional satisfaction, collaboration and sense of belonging (Elliot et al., 2020; McAlpine \& Amundsen, 2017; Melin \& Janson, 2006; Zweig et al., 2004). Researchers with foreign PhDs often continue projects internationally (Horta \& Yonezawa, 2013; Zweig et al., 2004). Their networks of former overseas workplaces may provide a supportive environment for greater international research productivity ( $\mathrm{Li}$ et al., 2018), although Horta et al. (2020) found that mobility experiences had no significant impact on overall productivity in the humanities and social sciences. Experience at a well-known institution is a typical form of social capital contributing to one's employability and career progression (Crossman \& Clarke, 2010; Li et al., 2018). Nevertheless, heavy reliance on international networks may prevent returnee ECRs from being recognized as a local community member (Ai \& Wang, 2017; Xu, 2009). Relationships with senior advocates can shelter returnees from uncooperative relationships and further increase their social capital (Li et al., 2018; Yi, 2011), but it appears that such relationships are often absent (Darmoe, 2017).

The research examined above has unpacked both the advantages and struggles of returnee ECRs serving institutions at home. ECRs are often encouraged to have international experience and develop effective capital to work in a globally competitive academia (Melin \& Janson, 2006). However, their competing sense-making of the capital they have gained remains under-researched. Even less is known about the sociocultural contexts contributing to their sense-making. Therefore, research on ECRs' conflicting sense-making requires a context-dependent individual-oriented scope. A study with this scope should encompass ECRs' diverse work responsibilities concerning intellectual, institutional and networking strands. 


\section{The Study}

\section{The Setting: Internationalisation and ECRs in Japan}

Globalisation is currently among Japanese universities' top concerns, but they have struggled with making sufficient progress. The government has implemented several grant schemes for universities to increase their international students, collaborations, English-taught programs and faculty members with international competence (Japan Society for the Promotion of Science, 2020). Nevertheless, the proportions of researchers from abroad or possessing international experience are still low (Franzoni et al., 2012; Kariya, 2017). Critics argue that institutional initiatives for internationalisation are unduly limited since universities often assign only a single department to make the effort (Kariya \& Yoshimi, 2020; Shimauchi, 2018). In social science, in particular, researchers have relatively little awareness of international scholarly outputs (Merga \& Mason, 2020).

The situation of ECRs' careers in Japan is uniquely alarming. For example, their actual responsibilities often diverge from their expectations. According to Kariya and Yoshimi (2020), Japanese faculty undertake a greater amount of administrative responsibilities than those in the UK and US. ECRs in social science mainly engage in administration and teaching, but little in research (Takagi, 2018). These examples indicate a stark difference from the international trend (Kariya, 2017; Kariya \& Yoshimi, 2020). Research work is considered important but not well supported practically by their institutions (Kariya \& Yoshimi, 2020; Takagi, 2018). 


\section{Research Tasks}

This study employs a reflexive, autoethnographic approach to probe ECRs' sensemaking of international experiences. Autoethnography is an approach using authors' own experiences, writing personal narratives and contributing to a gap in the literature (Chang, 2016; Lapadat, 2017; Le Roux, 2017). Narrative inquiries, in principle, explore meanings which individuals make of their experiences and offer an understanding of complex phenomena. Autoethnographic writing tries to explicate social dynamics wherein individuals reside, act and strive (Chang, 2016; Le Roux, 2017).

The following questions guided our inquiry: (1) how do we make sense of our academic international experiences while working as ECRs at Japanese universities, and (2) what conditions of our sociocultural environment have shaped our sense-making? The term "international experience" refers to our academic histories in which we crossed tangible and intangible boundaries of nations, languages and cultures. This includes study and work abroad, academic conferences, business visits and internships (Crossman \& Clarke, 2010). The definition of ECRs follows that of Japan Society for the Promotion of Science: individuals who have completed a $\mathrm{PhD}$ in the last eight years.

\section{Collaborative Autoethnography}

We, five Japanese ECRs having years of international experience, collaboratively conducted our inquiry (Chang, 2016). Taking an autoethnographic approach-emic approach to the phenomena under study — we engaged in both individual written reflections and collaborative self-reflexive dialogues. Collaborative effort enhances our reflexivity and research trustworthiness (Chang, 2016; Lapadat, 2017; Le Roux, 2017) and makes connections from our insights to wider settings (Lapadat, 2017). This effort 
also reduces the risk of unwanted consequences in disclosing personal episodes in our writing (Lapadat, 2017). Hence, this study makes our passion and voices heard in an academic community and suggests others face the realities of the authors (Ai \& Wang, 2017) and work together for future improvement (Le Roux, 2017).

We use pseudonyms to protect the anonymity of the people involved. Lui, Emily and Alan initially shared our interest in addressing our international experiences as an inquiry topic. We also invited Julie and George as they fit into the focus of the study. We all have international experiences as students in degree-granting programs or via exchange programs and share international education as a research field. We, all aged around forty, were born and received pre-tertiary education in Japan. Lui studied Japanese-as-a-second-language education in a Japanese undergraduate program. In his teens, he became interested in the subject owing to his short English study experience in the US. He wished to study more about language education at a master's program in Australia. After he graduated from the program, he worked as a lecturer in Malaysia and Egypt. He subsequently started his $\mathrm{PhD}$ in Europe. After the defence of his thesis, he was offered a fixed-term assistant professorship in Japan. He currently serves another university in Tokyo on a tenure-track contract.

During her undergraduate studies, Emily spent a year in the Netherlands as an exchange student. After receiving an English teaching certificate in Thailand and working there for several months, she moved to South Korea for two years, where she taught high school students who wanted to study at Japanese universities. This experience made her interested in student mobility and its impact on students' international understanding. For her master's and doctoral studies, she returned to her undergraduate university, where approximately $80 \%$ of students were international, and 
courses were offered in English. Currently, as an associate professor, she oversees an undergraduate program taught in English.

Julie worked as an administrator at a university after her bachelor's studies in Japan. While working for international students, she became interested in international education. She moved to the US to study educational psychology and higher education. After her PhD studies, she started her career as an assistant professor in Japan and served as an international education advisor. Several years on, she moved to another Japanese university with an assistant professorship at a department handling international exchanges. She currently teaches several courses in English and Japanese, coordinates incoming exchange and short programs.

Alan grew up in the countryside in Japan. He received his BA, MA and PhD in the US. During his graduate studies, he researched social issues surrounding racial minority groups, international education and English education. He is currently a fulltime faculty member in Tokyo. This job puts to good use his ten years of experience in the US, as well as his past seven years as a project-based academic at a large university, where he supported outbound students and expanded institutional partnerships for student exchange.

George's interests lie in empirical studies on the impact of international education at student and institutional levels. He became interested in the field in graduate school after working as a non-academic coordinator of international programs at a university in Japan. After completing his graduate studies in North America, he worked as an assistant professor in Japan for three years. He is currently an associate professor of an English-taught degree program. He has also served as an evaluation committee member of organisations offering international educational projects. 
We also invited an external researcher as a third-party commentator to deepen our reflective practices and bolster the quality of our study so that our writing would become more tangible and relevant to others (Chang, 2016; Le Roux, 2017). This researcher was invited because of her experience as an international postgraduate student and a researcher in international education. Le Roux (2017) emphasised the importance of writers' verisimilitude and ability to convey their subjective reality to readers as major elements of autoethnographic writing.

\section{Collaborative Sense-Making Processes}

The first author carefully outlined our goals, explained the division of work and arranged our meetings. Our reflexive processes via face-to-face and virtual meetings emphasised self-exploratory and co-constructive interaction (Chang, 2016). Our meeting started with sharing our biographic experiences as students, researchers, practitioners and teachers. We then generated our initial thoughts regarding international experiences and responsibilities at our respective institutions. The first author took notes of our meeting on an online spreadsheet for our reflexive talks later on.

In our second meeting, referring to the identity-trajectory framework, we broadly explored our experiences around the intellectual, institutional and networking strands. Via open conversations, which included asking each other questions, this “probing session" (Chang, 2016, p. 114) explored our experiences in depth and sought common themes underlying our diverse lived experiences. We also paid particular attention to contextualising our day-to-day work experiences where the meanings of our international experiences emerged. In our third meeting, we discussed the gaps, 
inconsistencies and authenticity of our stories. As a group, we collaboratively analysed our episodes, named the themes and (re)classified them.

In writing up, the first author composed the first draft, to which others added comments several times. Collaborative working facilitated the generation of complementary insights, which stimulated others and has helpfully enriched our manuscript. We adopted interpretive, analytic autoethnographic writing traditionally more common in the social sciences than evocative ones which invite readers to emotional arousal (Chang, 2016). As non-native English writers, we deliberately decided to do so, since evocative genres were linguistically beyond us. The following episodes often use they as a third-person singular to avoid the identification of individuals.

\section{Major Themes of International Experiences}

Our conversations converged on five major themes: global personal network, communicative competence, community culture, scholarly ambition and pedagogical application. The themes are often interrelated, which is to say, our responsibilities often simultaneously required different forms of capital—social and cultural—accumulated through our international experiences.

\section{Global Personal Network}

We make use of our global personal network cultivated through our international experiences to successfully undertake varied responsibilities. This social capital refers to our transborder relationships which emerge ubiquitously in our commitments. All of us have invited guest speakers from abroad for intellectual activities such as teaching and research seminars. Some have coordinated international symposiums, and our 
networks brought significant intellectual contributions. Lui, Alan and George have continued their collaboration with researchers with whom they worked while abroad. Interpersonal networks were also helpful for Emily and Lui in easing their anxiety at international conferences since there would be someone familiar present.

Furthermore, our networks are useful for our institutional tasks, specifically, for university bilateral agreements for exchange programs. Among us, George has most intensively worked on such an assignment and said, "Some agreements were created using my research networks, which also helped me further my educational network". Our global personal networks operate effectively in varied dimensions across our educational, intellectual and institutional tasks.

However, some of us commented on dilemmas regarding this social capital. Emily, Alan and Lui found that their network with local researchers was weak. One of them particularly felt uneasy about complicated relationships among senior researchers and said, "You cannot survive without being aware of their relationships". Lui also has little in the way of interpersonal networks in Japanese academia since he shifted his subject from Japanese language education to international education before his doctoral research and had no full-time domestic work experience prior. Weaker networks with local researchers and lack of opportunities to use our international networks have diminished the meaning of our international experiences. For instance, for some of us, main responsibilities included administrative work for study abroad arrangements, and one of us noted, unlike George, "My external networks have never been used. Our university does not use teachers' networks". In contrast, Julie has successfully built her connections with local researchers who have also had international sojourn experiences. 
She recollected, "Before my sojourn, I worked as administrative staff, and I appreciate the experience since I developed some networks with people in international education".

\section{Communicative Competence}

Our international experience was meaningful for our intercultural English communicative mindset and skills, although some dilemmas were expressed. The experiences allowed us to attain the cultural capital of skills and flexible attitudes which enable us to communicate with people from different backgrounds. We engage deeply in institutional internationalisation initiatives, for example, hosting visitors, chairing international events, corresponding with partner institutions and acting as committee members with international faculty. We feel supported by the trend that major Japanese universities lately require ECRs to have good communicative and teaching skills in English. We have recognised our communicative competence as meaningful in our responsibilities of teaching, research (intellectual) and management (institutional).

We see, however, some concerns vis-à-vis this cultural capital. Firstly, additional administrative duties have been allocated beyond our regular responsibilities simply because they were "international" tasks. Four of us expressed that, although we do not claim to be only interested in English-speaking duties, some tasks could be carried out by other staff members with little English skill. One of us was mandated to join "in some visits where I had no conversation with anyone" and wondered if they should attend. Another remarked that more staff members with English skills are necessary for effective internationalisation initiatives. Secondly, practical communicative competence seems to be valued unevenly in the same institutions. The English-medium course is still uncommon and not always evaluated positively. Three of 
us were disappointed to see some faculty members who showed resistance or

indifference to globalisation and prevailing English usage. One of us remarked, "Some people quibbled about my teaching in English and tried to find faults, ignoring all advantages". We also felt awkward about both students' and teachers' emphasis on "native speakerism". Lastly, we believe we have functional English skills, but think our communicative skills still have room for improvement. George maintained, "There are many other skilful staff in my department, and English per se has little advantage". We do recognise that communicative competence is just one dimension of cultural capital among many others.

\section{Scholarly Community Culture}

Our development during international experiences included acquiring different scholarly community cultures. This theme refers to cultural sensitivity in institutional diversity and integrity to encourage efficient outcomes. We nurtured this cultural capital in diverse settings and found it highly significant in our universities. However, while we have worked at Japanese universities for several years, three of us still experience stress owing to friction related to local institutional practices, for instance, frequent onerous meetings and bureaucratic decision-making processes. Another author was cognizant of the institutional climate where "you need to care about what others think of you". Other extreme episodes were shared by one who was dissatisfied with a climate where private funds were used for work, different ideas were disregarded in the name of "common sense" and colleagues were unhappy with others taking paid holidays. Another, however, expressed their dilemma: "Since I will continue working in Japan, I should be 
familiar with Japanese customs. My university appears international but largely follows traditional conventions inside. I somehow feel resigned. It's perhaps Japanese culture".

Julie and George, in contrast, have maneuvered their re-entry between different scholarly community cultures. They acknowledge some inefficient institutional practices, but one even sees tedious meetings as a means for institutional communication. The other explained that they had flexibly adjusted to different conventions, which helped them feel less distress. They explained their strategy: "I now believe that I should swiftly finish my duty without too much thinking", and said, "Any work may contribute to my development". They acknowledge that their work experiences in Japan before their sojourn helped them imagine how bureaucratic Japanese universities are in decision-making and administrative processes, which the others struggle with.

\section{Scholarly Ambition}

We participated in international academic communities as students and researchers and developed our scholarly ambition. This theme refers to our intellectual motivation to contribute globally to our fields of expertise. We have found our capital meaningful for our goal setting, but our experiences in carrying out our responsibilities have revealed some downsides to our ideal goals. During our international experiences, we witnessed researchers actively producing outputs internationally. Emily wrote, "Knowing the productivity and work of overseas ECRs ignites me". George similarly shared his passion: "I met researchers abroad who worked very hard to publish articles in international journals". Lui values his publishing experience with internationally-active researchers and said, "Seeing someone cite your papers motivates me". 
Although our international experience was a key driver for our scholarly ambition, the utility of the capital is largely context dependent. English writing requires substantially more time and is circumscribed by heavy non-research tasks. For Lui and Alan, research was not formally included in their job specification (institutional). It disappointed them and was a burden since research outputs were expected to be made outside of their work hours. Although George shared that some universities emphasise output in internationally-accredited journals for employment selection and promotion, our understanding of how English outputs are recognised in Japanese academia is somewhat cynical: English output has little advantage over Japanese works for career evaluation. One of us considers Japanese outputs to be expected of us for the local audience in the social sciences and humanities. Another has felt disappointed since researchers who can adequately evaluate English articles are limited in Japan.

\section{Pedagogical Application}

While studying and working abroad, we familiarised ourselves with pedagogical practices different from those we had encountered as students in Japan. We experienced student-centred pedagogy at overseas institutions, which we implement in our current teaching (intellectual). Alan, Emily and Lui felt empowered due to the current public endorsement of student-centred pedagogy in higher education. Furthermore, Julie and Lui consider that current secondary school graduates are responsive to this pedagogical style. George teaches in a small English-medium program, and the student-centred pedagogical style is suitable for them. Accordingly, our understanding of pedagogical practices resonates with and is supported by the current social expectation. In addition, three of us appreciated systematic research training experience. It is undeniably valuable 
for our own research. We have simultaneously recognised increasing societal attention to student research skills. Two of us feel that more attention to robust research design and theoretical contribution is necessary in research education in Japan.

\section{Methodological reflections}

Our collaborative effort with the commentator created more verisimilitude and coherence in our narrative since her comments paid extensive attention to what we had taken for granted. Nevertheless, our self-selection bias is undeniable, since, as researchers of international education, we are eager to promote the internationalisation of higher education. In addition, colleagues in the discipline generally have sympathy for internationally-trained ECRs. Moreover, researchers' identity is an ever-changing phenomenon (McAlpine \& Amundsen, 2017), and the meaning of mobility experiences is continuously influenced by their career pathways (Israel et al., 2019). Hence, our sense-making will differ in the future, and others in different disciplines, career stages and institutional settings may reach different understandings.

\section{General Discussion}

Our work illustrated five different themes in our sense-making of capital accumulated through our international experiences. The different forms of capital were closely intertwined with our responsibilities pertaining to intellectual, institutional and networking strands of the Identity Trajectory. Prior studies focused on undergraduate (e.g., Hanada, 2019; Ota \& Shimmi, 2019) and graduate students (Crossman \& Clarke, 2010; Elliot et al., 2020), and in many respects, we found similar advantages of cultural and social capital for ECRs. Global interpersonal network, which the literature has often espoused as the advantage of mobile researchers (Choi \& Lu, 2013; Li et al., 2018; 
Zweig et al., 2004) was useful not only in our research activities, but also in our teaching (intellectual) and institutional responsibilities. Our communicative skills are also of substantial value in our intellectual and institutional work. Moreover, we have familiarised ourselves with the mindset to contribute to international intellectual dialogues. This scholarly motivation corresponds with Chinese-born returnee ECRs (Ai, 2019; Ai \& Wang, 2017) who wished to maintain their identity as transborder researchers. Our reflection made us aware that our scholarly ambition was formed and re-formed, not only in study abroad experiences, but also in our casual interaction with researchers in short travels and in reference to international citation indices (networking).

The effect of international experience on researchers' pedagogical practices has been underexplored from a sociocultural perspective. Studies have shown, for example, that researchers with international experience adopted novel pedagogical approaches at home (Ai \& Wang, 2017) and used intellectual knowledge to diversify curricula (Choi \& Lu, 2013; Zweig et al., 2004). We believe that the current educational trend in Japan resonates with our cultural capital of pedagogical orientation, and we generally had a positive reaction from students. As such, societal understanding empowered us and made us evaluate our capital favourably. Similarly, our capital of English-medium instructional skills has been recognised as valuable in Japanese universities, but we also acknowledged that some people belittle its value.

Unpacking both positive and negative impacts of international experiences contributed to a fuller understanding of researcher mobility experience (Melin, 2005). For instance, Horta et al. (2020) presented mixed impacts of international experiences on researchers' productivity. Our skills in publishing in English — another kind of 
capital - are not always positively evaluated. Accordingly, we feel that it may limit the value of our international experiences. A study reported that traditional Japanese social science researchers were not concerned with international communities (Merga \& Mason, 2020). This situation has created confusion over which languages and scholarly communities we should rely on more (Ai, 2019; Ai \& Wang, 2017). Only a few external factors support us in utilising and developing the capital continuously, such as being aware of active overseas researchers and international indices of citation databases (networking).

Studies have reported mobile researchers' dilemmas navigating in different institutional cultures (Ai \& Wang, 2017; Elliot et al., 2020; Li et al., 2018). Some of us also felt uncomfortable facing new institutional conventions incompatible with our acquired capital. However, despite our disappointment, we have convinced ourselves to accommodate to them since we are highly likely to continue working in Japan. In contrast, a few others seldom experienced frustration as members of local communities. Our dialogues revealed that in these cases, their capital of international experiences was simultaneously associated with that of past domestic experiences, by which they work flexibly and positively. Different kinds of capital are utilised together to generate maximum benefits, allowing them to engage in their responsibilities with less distress.

While some of us have already forged sound relationships, the others felt themselves outsiders even in their homeland. It is vital, particularly for those who have struggled, to get support from local colleagues. Although Yi (2011) depicted returnee ECRs as reluctant to join a local scholarly network owing to locals' lack of international ambition, we are still interested in doing so. However, we found it difficult to join already-established local networks. Furthermore, Brotherhood et al. (2019) showed that 
some foreign ECRs in Japan found it unfeasible to develop a mutual rapport with local researchers (Brotherhood et al., 2019). Takagi (2018) likewise showed that Japanese returnee researchers expressed disconnection from their institutions. Accordingly, we would argue that foreign ECRs' poor sense of belonging in Japan results not only from being foreigners but also from an institutional climate unable to incorporate the "foreignness" of researchers with unique profiles.

Our autoethnographic inquiry illustrated our sense-making in our responsibilities as researchers, teachers, and practitioners. Different forms of capital were concurrently used to hold international intellectual events and were converted to new forms of capital acceptable in our current environment (Bourdieu, 1986), for example, new global networking and achievements in institutional responsibilities. While engaging in our responsibilities related to the institutional, networking and intellectual domains, we have updated our expertise, using the cultural and social capital that we gained in our international settings.

Furthermore, we contend that distinctive, competing meanings of our capital were generated, closely influenced by the conditions of local contexts. Melin (2005) suggested potential sub-cohorts of either satisfied or disappointed returnee scholars, but our study provides a distinct picture: we are satisfied and disappointed simultaneously. Our cultural and social capital has contributed to our multifaceted perception of both resources and challenges arising from our responsibilities. More interestingly, due to the absence of capital which could otherwise have been attained domestically (e.g., local networking and occupational culture), we occasionally recognised challenges and confusion in our intellectual commitments, networking and institutional settings. Namely, capital which could otherwise have been attained (domestically) may 
contribute to one's sense-making of capital that one actually attained (abroad). This theoretical understanding is insightful: capital is evaluated by the bearer with reference not only to the capital per se, but also to the opportunity cost of acquiring the capital.

\section{Implications for the Future}

Academics with international training can be a catalyst for institutional organisational reform (Choi \& Lu, 2013). Foreign and returnee ECRs in Japan have faced challenges in feeling a sense of belonging in scholarly communities. Perhaps, returnee ECRs like us should put more effort into building connections among researchers with diverse backgrounds (Kariya, 2017) via both formal and informal opportunities (Elliot et al.,

2020). Then, our capital can be used and further converted to new forms of capital. For that, systematic nationwide and institutional support is mandatory. Our reflection highlighted the sociocultural settings supporting or limiting the opportunities. If researchers find little value in their international experiences at their workplace, they may fail to further their expertise, and the government goal of nurturing world-class researchers will go unachieved. Perceived lack of support and enthusiasm may prompt them to seek other pastures where they may thrive.

We would also advise future returnees to bear in mind our challenges in returning home. A less-developed personal network at home is a typical problem for returnees (e.g., Turner \& McAlpine, 2011). International networking is valuable, but, in the current ECRs' precarious employment conditions, networking at home should also be attended to while travelling abroad. Furthermore, returnee ECRs should also be prepared for different, sometimes stressful, institutional climates and strive to deal positively with challenges (McAlpine \& Amundsen, 2017). We also agree that a 
proactive commitment to understanding local practices is important for career development (Xu, 2009).

Our role in advocating for the next generation of ECRs is crucial (Xu, 2009). Japanese researchers holding a foreign $\mathrm{PhD}$ were far more active in international knowledge circulation than those with PhDs from Japanese universities (Horta \& Yonezawa, 2013). We are still a minority in Japanese higher education, and institutional changes require a substantial amount of time (Choi \& Lu, 2013). Supportive senior advocates are vital for creating inclusive scholarly communities (Brotherhood et al., 2019; Darmoe, 2017; Li et al., 2018). Darmoe (2017) suggests that networking prevents returnee turnover within scholarly communities. We can serve as a positive agency to create Japanese scholarly communities where researchers with a unique global capital can flourish.

\section{References}

Ai, B. (2019). Pains and gains of working in chinese universities: An academic returnee's journey. Higher Education Research \& Development, 38(4), 661-673. https://doi.org/10.1080/07294360.2019.1590320

Ai, B., \& Wang, L. (2017). Homeland integration: An academic returnee's experiences in chinese universities. International Journal of Qualitative Methods, 16(1), 1-9. https://doi.org/10.1177/1609406917696741

Bourdieu, P. (1986). The forms of capital. In J. Richardson (Ed.), Handbook of theory and research for the sociology of education (pp. 241-258). Greenwood.

Brotherhood, T., Hammond, C. D., \& Kim, Y. (2019). Towards an actor-centered typology of internationalization: A study of junior international faculty in japanese universities. Higher Education, 79(3), 497-514. https://doi.org/10.1007/s10734-019-00420-5

Chang, H. (2016). Individual and collaborative autoethnography as method: A social scientist's perspective. In S. H. Jones, T. E. Adams, \& C. Ellis (Eds.), Handbook of autoethnography (pp. 107-122). Routledge. 
Choi, S.-J., \& Lu, J. (2013). Returnee faculty members, network position and diversification strategy: An analysis of business schools in china. Asia Pacific Business Review, 19(4), 559-577. https://doi.org/10.1080/13602381.2012.739361

Crossman, J. E., \& Clarke, M. (2010). International experience and graduate employability: Stakeholder perceptions on the connection. Higher Education, 59(5), 599-613. https://doi.org/10.1007/s10734-009-9268-z

Darmoe, J. (2017). The professor coming home determinants of retention of brain gain knowledge. International Journal of Management in Education, 11(2), 128-139. https://doi.org/10.1504/IJMIE.2017.083351

Elliot, D. L., Bengtsen, S. S., Guccione, K., \& Kobayashi, S. (2020). The hidden curriculum in doctoral education. Springer.

Franzoni, C., Scellato, G., \& Stephan, P. (2012). Foreign-born scientists: Mobility patterns for 16 countries. Nature Biotechnology, 30(12), 1250-1253. https://doi.org/10.1038/nbt.2449

Hanada, S. (2019). A quantitative assessment of japanese students' intercultural competence developed through study abroad programs. Journal of International Students, 9(4), 1015-1037. https://doi.org/10.32674/jis.v9i4.39

Horta, H., Jung, J., \& Santos, J. M. (2020). Mobility and research performance of academics in city-based higher education systems. Higher Education Policy, 33(3), 437-458. https://doi.org/10.1057/s41307-019-00173-X

Horta, H., \& Yonezawa, A. (2013). Going places: Exploring the impact of intra-sectoral mobility on research productivity and communication behaviors in japanese academia. Asia Pacific Education Review, 14(4), 537-547. https://doi.org/10.1007/s12564-013-9279-4

Horta, H., \& Yudkevich, M. (2016). The role of academic inbreeding in developing higher education systems: Challenges and possible solutions. Technological Forecasting and Social Change, 113, 363-372. https://doi.org/10.1016/j.techfore.2015.06.039

Israel, E., Cohen, N., \& Czamanski, D. (2019). Return on capital? Determinants of counter-migration among early career israeli stem researchers. PloS One, 14(8). https://doi.org/10.1371/journal.pone.0220609

Japan Society for the Promotion of Science. (2020). スーパーグローバル大学創成支援事業の中間評 価. Retrieved August 2 from https://www.jsps.go.jp/j-sgu/

Jonkers, K., \& Tijssen, R. (2008). Chinese researchers returning home: Impacts of international mobility on research collaboration and scientific productivity. Scientometrics, 77(2), 309-333. https://doi.org/10.1007/s11192-007-1971-X

Kariya, T. (2017). オックスフォードからの警鐘. Chuokoron-Shinsha.

Kariya, T., \& Yoshimi, S. (2020). 大学はもう死んでいる? Shueisha. 
Lapadat, J. C. (2017). Ethics in autoethnography and collaborative autoethnography. Qualitative Inquiry, 23(8), 589-603. https://doi.org/10.1177/1077800417704462

Le Roux, C. S. (2017). Exploring rigour in autoethnographic research. International Journal of Social Research Methodology, 20(2), 195-207. https://doi.org/10.1080/13645579.2016.1140965

Li, M., Yang, R., \& Wu, J. (2018). Translating transnational capital into professional development: A study of china's thousand youth talents scheme scholars. Asia Pacific Education Review, 19(2), 229-239. https://doi.org/10.1007/s12564-018-9533-x

McAlpine, L., \& Amundsen, C. (2011). Making meaning of diverse experiences: Constructing an identity through time. In Doctoral education: Research-based strategies for doctoral students, supervisors and administrators (pp. 173-183). Springer. https://doi.org/10.1007/978-94-007$\underline{0507-4 \_10}$

McAlpine, L., \& Amundsen, C. (2017). Identity-trajectories of early career researchers: Unpacking the post-phd experience. Palgrave Macmillan Limited. https://doi.org/10.1057/978-1-349-95287-8

Melin, G. (2005). The dark side of mobility: Negative experiences of doing a postdoc period abroad. Research Evaluation, 14(3), 229-237. https://doi.org/10.3152/147154405781776102

Melin, G., \& Janson, K. (2006). What skills and knowledge should a phd have? Changing preconditions for phd education and post doc work. In U. Teichler (Ed.), Wenner-gren international series: The formative years of scholars (pp. 105-118). Portland Press.

Merga, M., \& Mason, S. (2020). Sharing research with academia and beyond: Insights from early career researchers in australia and japan. Learned Publishing, 33(3), 277-286. https://doi.org/10.1002/leap.1296

Ota, H., \& Shimmi, Y. (2019). Recent trends in learning abroad in the context of a changing japanese economy and higher education situation. In R. Coelen \& C. Gribble (Eds.), Internationalization and employability in higher education (pp. 78-91). Routledge.

Portes, A. (1998). Social capital: Its origins and applications in modern sociology. Annual Review of Sociology, 24(1), 1-24. https://doi.org/10.1146/annurev.soc.24.1.1

Robles, G., \& Franzoni, A. L. (2015, July 6-9). Developing successful novice international faculty through a mentoring program. IEEE 15th International Conference on Advanced Learning Technologies, Hualien, Taiwan.

Shimauchi, S. (2018). English-medium instruction in the internationalization of higher education in japan: Rationales and issues. Educational Studies in Japan, 12, 77-90.

Takagi, K. (2018). Accommodating project-based professionals in higher education institutions in japan. Journal of Higher Education Policy and Management, 40(3), 272-286.

https://doi.org/10.1080/1360080x.2018.1462434 
Turner, G., \& McAlpine, L. (2011). Doctoral experience as researcher preparation: Activities, passion, status. International Journal for Researcher Development, 2(1), 46-60.

https://doi.org/10.1108/17597511111178014

Wang, B. (2020). A temporal gaze towards academic migration: Everyday times, lifetimes and temporal strategies amongst early career chinese academic returnees. Time \& Society, 29(1), 166-186. https://doi.org/10.1177/0961463X19873806

Xu, D. (2009). Opportunities and challenges for academic returnees in china. Asia Pacific Journal of Management, 26(1), 27-35. https://doi.org/10.1177/0961463X16682516

Yi, L. (2011). Auditing chinese higher education? The perspectives of returnee scholars in an elite university. International Journal of Educational Development, 31(5), 505-514.

https://doi.org/10.1016/j.ijedudev.2011.03.003

Zweig, D., Changgui, C., \& Rosen, S. (2004). Globalization and transnational human capital: Overseas and returnee scholars to china. The China Quarterly, 179, 735-757. 